\title{
A Review of Arlie Russell Hochschild's Strangers in their Own Land: Anger and Mourning on the American Right (2016: New York: New Press, 351pp)
}

\author{
William Davies ${ }^{1}$
}

Published online: 5 July 2017

(C) The Author(s) 2017. This article is an open access publication

Following the 2016 referendum on the UK's membership of the European Union, a new map of Britain appeared. All the areas of the country that had voted 'Leave' were marked in blue, while all those that had voted 'Remain' were marked in yellow. The most obvious elements of the emerging cultural and political geography were unsurprising. Scotland and most of Northern Ireland were predictably yellow, as was London, where 'Remain' recorded its highest shares of the vote. Most of rural England and Wales were blue. But beyond these big blobs of colour, something more subtle and sociologically intriguing could be traced as well.

One interesting phenomenon was the big blob of yellow, which ran westwards out of London towards Oxford and Bristol. This is a highly networked region, well-connected to Heathrow airport and attractive to foreign direct investment by multinational corporations. Microsoft, for example, has a base in Reading, located along the highly prosperous Thames Valley. Look even more closely at the map, and something else appears: Amidst large seas of blue, there are flecks of yellow representing smaller cities such as Leicester, Exeter, Newcastle and Norwich. And one thing these cities all possess is a university.

Of course there is a risk of reifying geographic and cultural divides, and one should be wary of hasty theorisation. The presence or absence of a university did not cause an area's vote one way or the other, and does not explain the result. However, a slight pattern is nevertheless discernible which invites reflection. Universities are connected to one another at a global scale, operating with forms of abstract knowledge and esoteric languages, not entirely unlike financial services. They employ people who specialise in 'knowing that', but not necessarily in 'knowing how'. They generate trust on the basis of formal credentials and empirical records, not on the basis of identity or shared myth. It is a cliché encouraged by conservatives that academics are all left-leaning liberals who are obsessed with 'political correctness'. But it must surely be the case that the spatial and cultural horizons of an academic's day-to-day working

An author's reply to this comment is available at doi:10.1007/s10767-017-9266-6.

William Davies

w.davies@gold.ac.uk

1 Goldsmiths, University of London, London, UK 
life are more extensive than average, even if that is only experienced via narrow channels of peer review, conferences and email. Universities are multinational environments. Like the highly-trained 'knowledge workers' located in that yellow blob between London, Bristol and Oxford, academics regularly travel overseas as part of their work and potentially operate in a global labour market, producing knowledge that is as valid in Shanghai as it is in New York.

Confronted by that blue and yellow map of 'Brexit Britain', UK-based academics might be forgiven for asking themselves the following: are we now the enemy? Is a commitment to generalizable theory, evidence and method now a trigger for antipathy? In her study of rural Wisconsin, The Politics of Resentment, Katherine Cramer discovered that the privileges of academic life, together with the status universities confer, had indeed generated considerable resentment in marginalised rural communities. Asked their views of University of WisconsinMadison, one replied:

They don't want anything to do with ya. They think they're smarter than ya. Got that book learning. People go to college they come out dumber than they went in. They got the books there, those books, it's not like the experience (Cramer, 2016: 126).

In an age of populism, this sense of alienation cuts both ways. I have plenty of non-British UK-based friends and colleagues who have felt isolated and vilified since the referendum. At the time of writing, it is not clear what the future holds for EU citizens resident in the UK and this uncertainty wreaks social and psychological harm. Understandably, those affected by this do not separate their emotional response to Brexit from their political, sociological and economic analysis - partly because they can't, and partly because they don't see why they should. They are angry and hurt. Meanwhile, the only academics I know who saw the referendum result coming are those who had themselves spent long periods living in those big seas of blue. In all manner of ways, everything has suddenly got rather personal.

The political upheavals of 2016 have provoked much debate amongst social scientists and commentators regarding the nature and causes of 'populism'. This discussion is only completely honest if it includes a degree of reflexivity, that is, if it considers the extent to which intellectualism, theory, abstraction, aggregation, expertise and Cartesian detachment have played some part in provoking the populism we see today. Academics can generate all the theories they like about events such as Brexit or Trump, but we are also inescapably part of this story, whether that be as the privileged 'elite' which populists are venting their resentment towards, or as the victims of a new anti-global politics which seeks to re-build national boundaries, or as something else altogether. What might that 'something else' look like? Arlie Russell Hochschild provides one shining example.

To describe Strangers in their Own Land as 'prescient' risks doing it a disservice, as if the book's main achievement is in having predicted the political outbursts that occurred around the time of its publication. Hochschild acknowledges late on in the book 'looking back at my previous research, I see that the scene had been set for Trump's rise, like kindling before a match is lit' (p. 221). But the ethnography underlying the book lasted 5 years, meaning that it must have begun in late 2010 , initially provoked by a sense that 'blue states' and 'red states' were bifurcating in unprecedented and increasingly troubling ways, symptomized by the appearance of the Tea Party. For this reason, Hochschild selected Louisiana as the site of her ethnography, partly because of the strength of conservativism in the state, but also the widespread hostility to government. These traits exist despite it being a state that depends heavily on Federal spending and one which arguably benefits from Federal regulations (especially environmental and employee protections) more than most. This apparent 
contradiction is what she terms the 'great paradox', the understanding of which provides her central research problem.

Trumpologists have tended to focus more on the Midwestern states that swung unexpectedly to Trump in the 2016 presidential election (such as Michigan) and the former mining regions of Appalachia, where sheer despair seems to have outweighed the implausibility of Trump's policies. Louisiana doesn't provide the same keyhole into Trump's victory as such. What I think Hochschild does give us, and what makes this far more than a book with political 'prescience', is a critical meditation on the relationship of the social sciences to those parts of 'society' that it is far easier to theorise than it is to truly know. This is knowing in the sense of the French word connaitre (in the way one knows another person), rather than savoir (in the way one knows a fact). And as with any interpersonal relationship, it makes demands of both parties, requiring them to overcome or accept certain differences as they go. Other than the odd joke about her being a Berkeley 'communist', Hochschild appears to have encountered relatively little suspicion (in contrast to the above quote in Cramer's book), which is testimony to the patience and seriousness of her ethnographic project, as well as to the conviviality of her research subjects. This is a story of how separate cultural worlds might be brought into contact with one another, not so much colliding (a metaphor that better describes more drive-by forms of social research, including those carried out by government) but edging hopefully if cautiously towards each other.

Hochschild tells us that she was inspired by Thomas Frank's 2004 book What's the Matter With Kansas? which had explored how and why working class American communities had voted against their economic interests since the 1970s. Frank's analysis is superb, but it also reinforces some epistemological categories and binaries whose usefulness may now be waning. Put simply, this comes down to a separation of 'economic' from 'cultural' (or 'moral') issues, the argument being that the Republican Party has brilliantly exploited the 'culture wars' to push through an aggressively pro-business economic agenda, including tax cuts for the very rich, persuading the white working class to vote for it through appealing to their 'values'. It is impossible to deny the core truth in this analysis, especially when considering the George W. Bush era of the early 2000s when Frank was writing. But Hochschild manages to get underneath the abstractions, to lived experiences which do not split tidily into 'cultural' and 'economic' categories. At ground level, where Hochschild works, the economic, the cultural and the moral are impossible to disentangle. In that sense, Strangers in their Own Land can be read as a piece of cultural economy and moral economy, and a rebuke to any critical realists seeking to distinguish real economic interests from ideology.

How, then, can we make sense of 'the great paradox', if not in terms of the traditional categories of the 'culture wars' or 'false consciousness'? How can it be reasonable (if not quite rational) and understandable to oppose the very government services and interventions which might credibly improve people's physical and economic wellbeing, preserve their much-loved natural habitat and defend them from opportunistic businesses? This is a question which resonates well beyond Louisiana, indeed well beyond the USA. It is one of the central sociological and political questions posed by the Brexit referendum, the outcome of which is frequently described as an astonishing act of 'self-harm', albeit in a primarily economic sense. Hochschild's ethnography traces many visceral and visually striking examples of other forms of harm, which could have been prevented if only environmental regulators were better empowered and if ruthless companies had been restrained. Fish are no longer the same colour as they used to be in living memory; the croaking of frogs has fallen silent. Fracking has caused a sink hole to open up, offering the most literal demonstration of the natural limits to 
extractive industry. Yet Washington DC remains the villain in the eyes of her research subjects, and only rarely big business.

As she gets inside their world, Hochschild discovers a fierce sense of morality that, oddly enough, is more at ease with destructive capitalism than it is with liberal policy or regulation. It's not that her interviewees don't know that business has caused the pollution and threatens their health and safety. But business is honest about its function. As one tells her 'a company has a job to do; it's making things people want and need. Just like people have to go to the bathroom, plants do too. You can't just say "don't do it"' (p. 166). Pollution is as natural as urination; the Environmental Protection Agency is in denial. It is widely accepted that business is greedy, but there is something naked about this. Another tells Hochschild that it is inevitable that polluters should try to 'cover their ass' (p. 108) and avoid accepting liability. Those living with the day-to-day reality of pollution don't want to be lectured by experts or regulators about risk and welfare, when they've experienced the physical and environmental harms at firsthand.

This brute realism about capitalism contains ample truth within it that is not so different from the harsh perspective of, say, Georges Bataille, for whom there is always an 'accursed share' which suffers the consequences of endless accumulation. While liberals and environmentalists seek out 'win-win' policy solutions, which balance 'efficiency' with 'equity', or 'growth' with 'sustainability', these Louisianans throw serious doubts about such happy outcomes. The accumulation of wealth involves extraction, and there is not an infinite supply of natural or human resources to extract from. Consumption requires destruction; risk-taking requires occasional catastrophe. That's our economic reality. It's not pleasant, but let's not pretend otherwise. This might sound nihilistic, but there is an underlying moral logic of reaping what you sow, in a game of existential survival. Odd as it may sound, there may actually be something that the environmental movement could learn from these reports, regarding the moral economy of resource extraction and how the consequences are felt. For these people, there is nothing abstract or statistical about natural devastation: it is a visceral, material fact of daily life. Many are climate change deniers, but they are far from oblivious to what industry is doing to the non-human world, and arguably far more immersed in this painful reality than 'we' who look at satellite images of polar ice-caps on CNN. We discovered the 'anthropocene' in recent years, while they've dwelt there all along.

Capitalism, from this perspective, is punitive, selfish but honest. It delivers the goods and the occasional harms you expect. Government, meanwhile, is kind, altruistic but dishonest. It fails to deliver on its promises. Those in Washington who speak of consumer protection, environmental protection and 'fairness' not only threaten to harm employers (including all those egregious polluters), they are incapable of applying these norms in any consistent fashion. Ultimately, their plans are all just talk. As Hannah Arendt remarked, rage is more often provoked by a sense of hypocrisy than one of injustice. Hochschild reveals complex webs of moral-economic obligation operating within religious congregations, families and communities. There is plenty of what David Graeber calls 'baseline communism' at work in these Louisianan communities. But the Federal government is viewed as an anathema to all this, facilitating delinquency and worklessness, allowing people to renege on their moral contracts on which true American community is built. It is a threat to what survives of a traditional moral order, and, unlike capitalism, the damage it does is intentional, driven by the moral relativism of liberals. One of Hochschild's many fascinating observations is that 'government also functions as a curious status-making machine. The less you depend on it, the higher your status' (p. 114). 
Sociologists have a habit of invoking metaphysics to explain what they cannot understand. Whether it be 'ideological superstructure', the 'spirit of capitalism' or some intangible value substance, it is tempting to reach for something invisible and intangible when people are acting against their apparent interests. By the same token, evangelical Christianity provides secular liberals with a way of understanding the political success of conservatism over recent decades, a kind of 'othering' that has contributed to the bifurcation that Hochschild is determined to transcend. Interestingly, God and theology play a surprisingly marginal role in her account. Christianity is in there, but as a set of day-to-day practices and obligations, not as something unworldly. There is a strong sense of tradition and of right and wrong, but it is accredited to place, family, America and memory more than to the bible or Jesus Christ. It provides a necessary way of navigating prosaic everyday dilemmas, hardships and injuries. It makes sense of the world for them, just as sociology does for Hochschild and her readers. The ingredients of this sense-making apparatus are rarely exotic or mystical, which makes me wonder if the political influence granted to evangelism over the past 30 years might have been exaggerated to a certain extent. The church is one feature of this moral-economic landscape, but so is work, family, luck and nature.

The term Hochschild introduces to capture this meaning-making facility is 'the deep story', which 'tells us how things feel' (p. 135). This appears in the middle and pivotal chapter of the book, and she offers a version of her research subjects' 'deep story' based on a simple metaphor of waiting in line. America is a harsh country, but it eventually offers rewards to those who are patient, disciplined and determined. In that sense, the American dream is like waiting in line: It isn't just a free lunch, but takes respect, self-control and resilience. Yet for all manner of reasons, to do with welfare, immigration, globalisation and identity politics, the rules of waiting in line no longer seem to be properly upheld, at least from the perspective of these poor rural Louisianans. Some people are cutting in, sometimes the line seems to be moving backwards, and those overseeing the line (federal government) don't seem to have any recollection of how long some people have been waiting nor any respect for their powers of self-discipline. Liberals seem to feel far more sympathy for the person who can't wait, than they do for the one who can. Worst of all, they make it obligatory for everyone else to share that sympathy ('political correctness').

Hochschild tries out this metaphor on some of her interviewees and discovers some remarkable resonances. 'I live your analogy' says one. 'You have read my mind', says another. This is the moment in the book where the author's tenacious quest for empathy suddenly pays dividends. She later uses 'the deep story' to make sense of Trump: Here was a man who channelled the rage of those waiting endlessly in line, and promised-finally-to grant them their dues, get them to the front and clamp down on those cutting in. From the perspective of her own 'deep story', of course, those 'line-cutters' are minorities struggling against centuries of systemic oppression or people fleeing something far worse than poverty. She suspends her own judgement admirably well, although this suppression of critique and empirics carries risks with it too: She follows their emotional story through various twists and turns, which include crypto-racist value judgements. Hochschild handles this with great care, but the question inevitably arises of what the vocation of sociology should be in this respect.

The turn to 'the deep story' is a brilliant means of helping the reader over the 'empathy wall' that Hochschild made it her challenge to scale. But I was curious to know exactly what status we should accord to such a narrative. It's not quite psychoanalytic, but nor is it a myth that is told by the community's members. It appears like a kind of theoretical fiction, perhaps not unlike a Weberian 'ideal type' that is introduced by the sociologist to create a common world with research subjects. A criterion of a valid 'deep story' might therefore be that it is 
recognised by its inhabitants, while also being communicable to non-inhabitants, performing a pragmatic, Habermasian function of rescuing a common public realm. Perhaps the sociologist becomes a hybrid of psychoanalyst, translator, anthropologist and public intellectual (or even a relationship counsellor!) whose powers of patient listening and re-framing help to knit worlds back together again. The book ends with a letter to liberals then another to Hochschilds now friends in Louisiana, inviting each to consider the other's point of view. Of course this is no replacement for the hard graft of politics, much of which goes on in the grubby world of Washington DC, but it is a small step towards repairing deep-set enmities. It would be interesting to know whether there is evidence of it working (on either side of the 'empathy wall'), in the time since the book's publication.

A further question I had concerned the specificity of 'the deep story'. As told by Hochschild - ventriloquizing her interviewees - it is an American story, but I suspect that it would resonate in many of the de-industrialised regions in the developed world where populist conservatives have recently made significant in-roads. The belief (in defiance of all evidence) that welfare and regulation exists primarily to benefit immigrants, criminals and fraudsters is one that 'feels true' for large swathes of European populations, who have never been granted a replacement source of economic pride since the decline of manufacturing and mining. Social scientists across the Western world are now having to grapple with the challenges and questions that Hochschild has confronted, but there are multiple ways of doing so. Many of them strengthen binary divisions, reinforcing the sense of 'the white working class' as a separate and unreasonable subculture (The Economist magazine even went as far as introducing a 'white working class' index in early 2017). Others offer superficial defences of 'nativist' concerns, arguing that people are entirely justified in opposing minority rights, welfare and immigration. This only serves to alienate liberals from their communities, having the reverse effect of turning us into 'strangers in our own land'. Neither of these options is very inviting, however few of us have the luxury of spending 5 years on an ethnography, or indeed the tenacity to do so. If sociology is analogous to therapy (being what Les Back terms a 'listener's art'), maybe we need a psychodynamic middle ground between Freudian analysis (unearthing 'deep stories' over 5 years) and Cognitive Behavioural Therapy (drive-by social research via polling and focus group).

How sociologists can and should approach their fellow citizens is partly shaped by the health of the public realm more broadly. Hochschild has deliberately gone in search of fellow Americans who are most aggrieved with the direction of their country, and have least in common with the values and perspective of a Berkeley sociologist. She provides plenty of explanation for why this has happened, dating back to the 1860 s, and including the terrifying monopoly of Fox news in conservative communities. The height of the 'empathy wall' is partly, therefore, a symptom of endemic failures in other aspects of the 'American experiment', especially in relation to media power and lobbying. The latter is not a topic that comes up in Hochschild's discussions, but it is a political failure that validates at least some of the hostility the Louisianans feel towards Washington DC. After all, one of Trump's most famous campaign slogans was 'drain the swamp', though of course he has done quite the opposite since taking office. If democracy were healthier, if media were less manipulative, perhaps empathy wouldn't be worth quite so much sociological effort. I realise that's a counterfactual, but it indicates something about the status of sociology in relation to public life: as the latter becomes corrupted, the former must delve further into the private realm in search of some future public.

On the other hand, Trump's unexpected victory in November 2016 potentially casts another light on the politics of empathy and 'deep stories'. As has been tirelessly discussed in the liberal 
media, Trump seems to have no regard for facts, in the modern empirical sense of the term. As Hochschild explains, a deep story removes fact, and Trump is a master of this, even while he does nothing to actually help those people patiently 'waiting in line'. There is nothing necessarily politically complicit about empathising with how something feels to another (Hochschild, one assumes, is no less liberal now than she was in 2010), but nor does this project necessarily offer very much political resistance of any kind. Populism is producing curious new alliances, as indicated by those yellow blobs on the map of the UK, where academics, bankers, business lobbies and human rights activists are all suddenly on the same side of an argument. Sociologists tend to treat 'positivism' as a pejorative term, but if the alternative is 'Trumpism' then most would rather get into bed with the behaviourists and the statisticians. Again, there's the unwelcome binary, the like of which Hochschild wants to avoid. But what does empathy offer in this unpleasant new state of affairs? I'm curious to know what the underlying political or public commitment is here. Perhaps the message offers more to scholars who are already died-in-thewool positivists (including non-sociologists) than to those who are already attuned to issues of perspectivism, culture and the social construction of knowledge. But would such scientists be open to such a dialogue? They might be more sympathetic to Hilary Clinton, when she described many of Trump's supporters as a 'basket of deplorables'. This is where Hochschild's brief 'letter to a friend on the liberal left' becomes crucial.

I want to finish by offering a slightly different interpretation of Hochschild's findings, which is not in any way a contradiction of hers, indeed it emerges entirely from reading the book. But it is rooted more in questions of political economy than of affect. As I read Strangers in their own Land, I kept wondering if this was also a book about the modern business corporation and its discontents. The power of corporations lies in their ability to constantly evade tidy categorisation, to switch between moral and amoral rhetorics as it suits them, while often behaving immorally as they do so. They are vast bureaucracies, yet they are also risktaking 'enterprises'; they are huge collectives, yet also legal 'persons'; they are competing in a market, while eliminating or buying the competition; they exist in an apolitical space called 'the economy', while routinely shaping or blocking legislation via lobbying networks; some of their senior managers are amongst the richest people in the world, but somehow they never count as 'the elite'. Here lies another 'great paradox', which may not be unrelated to the one Hochschild is interested in. Every time you try to nail down the status of corporations in one way, they morph into something else.

So much of the pain and the hope experienced by Hochschild's discussants come down to the whims of corporations. Corporations arrive offering jobs, though never quite as many as first hoped, then leave behind a trail of pollution and unemployment. For complicated reasons, this is viewed as natural and unavoidable, whereas efforts to regulate it differently are unnatural and implausible. One of these reasons is that via the unhelpful umbrella concept of business, any small businessman or anyone struggling to make a buck is able to empathise with these vast hulks of extractive capital. Absurdly, all parties are perceived as equals, as if the BP oil spill in the gulf of Mexico - a direct result of cost-cutting due to pursuit of shareholder value - was on a moral plane with the small-scale mistakes or grey market activity of a selfemployed man struggling to get by, purely because both operate in some abstraction called 'the market'. Part of the perceived hypocrisy of regulators is they come down hard on miscreants who they are able to catch and punish, and leave alone those who they can't-i.e. multinationals, with legal muscle and political connections.

These issues are all present in Hochschild's narrative, and arise at the end of her telling of 'the deep story' - though largely as issues that are absent from that story. Big business is not 
'waiting in line' along with everyone else, but nor does it manipulate the line according to its own moral prejudices like government does. It exists in some parallel deep story called 'the free market', which is perceived as fair in and of itself. The problem with both 'deep stories' is that still hark back to a nineteenth century, pre-managerial economic world. If there were to be a revival of left-wing populism, of a sort that might appeal to some of the Louisianans in Hochschild's book, some further re-narration of 'the deep story' might be required. A deep story that helped distinguish between corporate capital and small business, between the fairness of market exchange and the rampant unfairness of oligopolistic control, needs unearthing. Strangers in their Own Land is partly a story of how authentic ethical ideals become entangled with destructive and sometimes self-destructive political commitments, over long periods of time. Hochschild's gift is to help us understand that. The disentangling is even harder, but one place to start would be by illuminating the duplicitous moral logic of the corporate form.

Open Access This article is distributed under the terms of the Creative Commons Attribution 4.0 International License (http://creativecommons.org/licenses/by/4.0/), which permits unrestricted use, distribution, and reproduction in any medium, provided you give appropriate credit to the original author(s) and the source, provide a link to the Creative Commons license, and indicate if changes were made. 